Check for updates

Cite this: Chem. Sci., 2019, 10, 3840

๑ All publication charges for this article have been paid for by the Royal Society of Chemistry

Received 13th December 2018 Accepted 20th February 2019

DOI: $10.1039 / c 8 s c 05518 a$

rsc.li/chemical-science

\section{2-Bromo-6-(chlorodiisopropylsilyl)phenyl tosylate as an efficient platform for intramolecular benzyne-diene [4 + 2] cycloaddition $\uparrow$}

\author{
Arata Nishii, ${ }^{a}$ Hiroshi Takikawa (iD b and Keisuke Suzuki (iD *a
}

An intramolecular benzyne-diene [4 +2 ] cycloaddition with broad substrate scope has been realized by using a cleavable silicon tether, allowing access to various polycyclic structures. 2-Bromo-6(chlorodiisopropylsilyl)phenyl tosylate serves as an efficient platform for (1) rapid attachment of various arynophiles to the benzyne precursor via a $\mathrm{Si}-\mathrm{O}$ bond and (2) facile generation of benzyne via halogenmetal exchange with $\mathrm{Ph}_{3} \mathrm{MgLi}$.

\section{Introduction}

Benzyne is a highly reactive species with a distorted formal triple bond. ${ }^{1,2}$ The frontier orbital is the unusually low-lying LUMO, that is the origin of four representative reactivities, (1) $[4+2]$ cycloaddition, (2) [2+2] cycloaddition, (3) ene reaction, and (4) addition of a nucleophile. Among these, the $[4+2]$ cycloaddition is useful for constructing benzo-fused six-membered rings embedded in various natural/unnatural products. ${ }^{2 h-o}$ However, two major problems have stymied further advances in synthetic applications. (1) Periselectivity: the $[4+2]$ reactions, in particular of carbocyclic dienes or acyclic dienes, are often accompanied by competing [2+2] and ene reactions (Fig. 1a). ${ }^{3}$ (2) Regioselectivity: the formation and the ratio of two potential regioisomers depend on the steric and electronic effects of substituents A and B (Fig. 1b). Moreover, an effective frontier orbital interaction is essential for a successful $[4+2]$ cycloaddition. Hence the diene component usually requires a high-lying HOMO and a constrained $s$-cis geometry, which are typically provided by a cyclic framework while limiting the scope of this reaction.

One of the solutions to overcome these issues is to exploit the intramolecular reaction by tethering the benzyne progenitors to the dienes (Fig. 1c and Scheme 1). ${ }^{4}$ While furans are the most commonly used arynophiles for the intramolecular $[4+2]$ cycloaddition as initially demonstrated by Wege, ${ }^{4 a}$ reactions with carbocyclic or acyclic dienes are rare. An early study by Buszek ${ }^{4 c, d}$ exemplifies the carbon tether for the benzyne-diene cycloaddition (Scheme 1a), which has later been investigated by Smith with the union of the anion relay chemistry (Scheme 1b). ${ }^{4 g}$

${ }^{a}$ Department of Chemistry, Tokyo Institute of Technology, 2-12-1 O-okayama, Meguro-ku, Tokyo 152-8551, Japan. E-mail: ksuzuki@chem.titech.ac.jp

${ }^{b}$ Graduate School of Pharmaceutical Sciences, Kyoto University, Yoshida, Sakyo-ku, Kyoto 606-8501, Japan

$\dagger$ Electronic supplementary information (ESI) available. See DOI: 10.1039/c8sc05518a
Danheiser reported an efficient intramolecular $[4+2]$ cycloaddition of a benzyne with an acyclic diene by employing a nitrogen tether (Scheme 1c). ${ }^{4 f}$ Concerning a disposable linker, ${ }^{5}$ Martin pioneered the application of the silicon tether, connecting the benzyne precursor with the arynophile via a Si-C bond. ${ }^{4 e}$ However, furans were the only arynophiles used in the study and the method was elegantly exploited in the syntheses of various aryl $C$-glycoside natural products (Scheme $1 \mathrm{~d}){ }^{6}$

In this context, we have focused our efforts on developing a viable strategy to further expand the utility of the intramolecular benzyne-diene $[4+2]$ cycloaddition. Herein, we report a practical, robust implementation of this reaction by exploiting arylsilyl chloride I as a novel benzyne platform (Scheme 1e). Arylsilyl chloride I having a silicon atom directly attached to the benzyne precursor allows a facile assembly with the diene partner II having a pendant hydroxy group via a $\mathrm{Si}-\mathrm{O}$ linkage under mild conditions to give cycloaddition precursor III. This strategy provides the following advantages: (1) the vicinal halogen-sulfonate functionalities of compound III allow facile benzyne generation initiated by a halogen-metal exchange $^{4 \boldsymbol{b}, \boldsymbol{h}, \boldsymbol{i}, \boldsymbol{7}}$ followed by the intramolecular cycloaddition. (2) The broad substrate scope resulting from various combinations of I and II gives useful cycloadduct IV that is amenable to numerous potential elaborations.

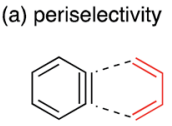

[4+2]

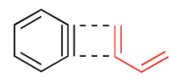

[2+2] (b) regioselectivity

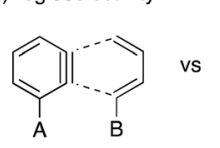

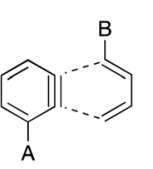

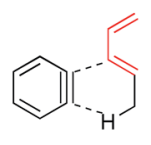

ene reaction

(c) tethering

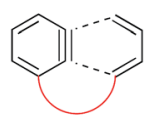

Fig. 1 Peri- and regioselectivity of the benzyne reaction with dienes. 
(a) Buszek<smiles>Brc1ccccc1CCCC1=CC=CCC1</smiles>

(b) Smith

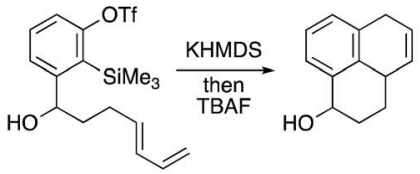

(c) Danheiser

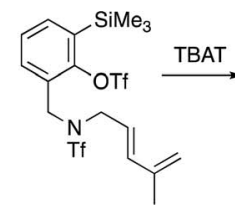

(d) Martin

(e) This Work

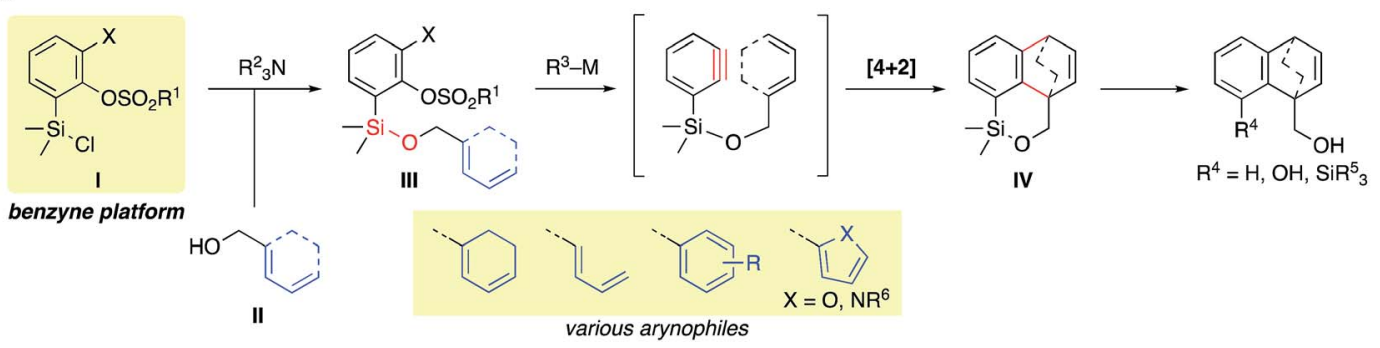

Scheme 1 Overview of the reported intramolecular [4 +2] cycloaddition of benzyne with dienes (top) and our strategy (bottom).

\section{Results and discussion}

Scheme 2 shows the preparation of the model substrate 6a. 2,6Dibromophenol (1a) was silylated with diisopropylsilyl chloride to give the corresponding silyl ether, which was treated with $n$-BuLi to induce a retro-Brook rearrangement ${ }^{8}$ to give $o$-silyl phenol $2 \mathrm{a}$ in $87 \%$ yield. Treatment of phenol $2 \mathrm{a}$ with $\mathrm{TsCl}\left(\mathrm{K}_{2} \mathrm{CO}_{3}\right.$, acetone, $0{ }^{\circ} \mathrm{C}$ $\rightarrow$ RT, $1.5 \mathrm{~h}$ ) gave tosylate $3 \mathrm{a}$ in excellent yield, ${ }^{9}$ which reacted with trichloroisocyanuric acid (TCCA), giving silyl chloride $\mathbf{4 a}$ in quantitative yield.$^{10}$ It turned out that $\mathbf{4 a}$, once obtained as a white solid, was stable enough for storage over several months (at $-15^{\circ} \mathrm{C}$ ).

Silyl chloride 4 a, thus obtained, served as a platform to combine various dienyl alcohols to give the cycloaddition precursors, as illustrated by the preparation of the model substrate $6 \mathbf{a}$. In the presence of imidazole, $\mathbf{4 a}$ was combined with alcohol $\mathbf{5 a}$ having a cyclohexadienyl moiety to give silyl ether $6 \mathbf{a}$ in $80 \%$ yield.

Having $\mathbf{6 a}$ in hand, the intramolecular $[4+2]$ cycloaddition was examined (Table 1). As the initial experiment, 6a was treated with $n$-BuLi (THF, $0{ }^{\circ} \mathrm{C}, 20 \mathrm{~min}$ ), where the desired cycloadduct 7a was obtained in 53\% yield (entry 1 ). The starting material 6 a was recovered in $5 \%$ yield, and a side product 8 was obtained in $c a$. $8 \%$ yield, arising from the addition of a butyl anion to the benzyne followed by the protonation or $\mathrm{Br}-\mathrm{Li}$ exchange reaction of

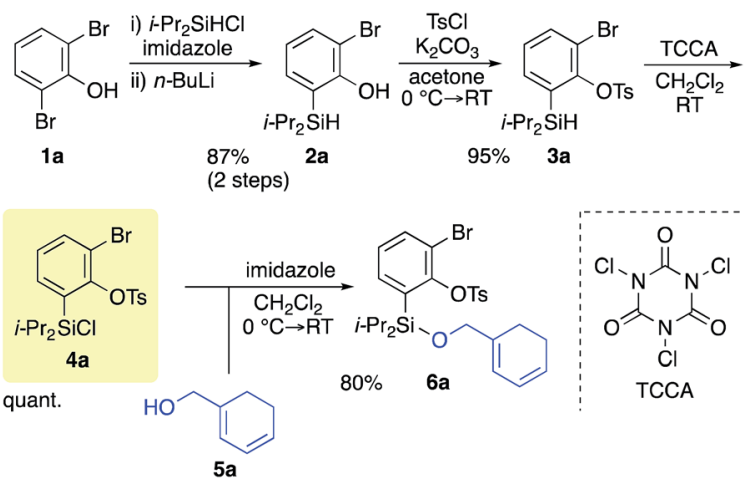

Scheme 2 Preparation of the benzyne platform 4a and union with alcohol $5 a$.
Table 1 Optimization of the reaction conditions with tosylate $6 a$
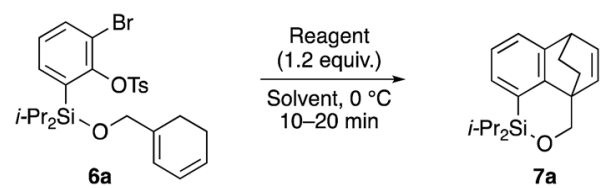

\begin{tabular}{|c|c|c|c|c|}
\hline Entry & Reagent & Solvent & Yield $^{a}$ of $7 \mathbf{a}(\%)$ & Recovery $^{a}(\%)$ \\
\hline 1 & n-BuLi & THF & 53 & 5 \\
\hline 2 & $s$-BuLi & THF & 35 & 25 \\
\hline 3 & PhLi & THF & 52 & - \\
\hline $4^{b}$ & $i$-PrMgCl & THF & 37 & 41 \\
\hline 5 & $\mathrm{Ph}_{3} \mathrm{MgLi}$ & $\mathrm{THF}$ & 69 & - \\
\hline 6 & $\mathrm{Ph}_{3} \mathrm{MgLi}$ & $\mathrm{Et}_{2} \mathrm{O}$ & 87 & - \\
\hline 7 & $\mathrm{Ph}_{3} \mathrm{MgLi}$ & TBME & 81 & - \\
\hline 8 & $\mathrm{Ph}_{3} \mathrm{MgLi}$ & CPME & 82 & - \\
\hline 9 & $\mathrm{Ph}_{3} \mathrm{MgLi}$ & $n-\mathrm{Bu}_{2} \mathrm{O}$ & 83 & - \\
\hline
\end{tabular}

the resulting aryl anion. Notably, no other byproducts, derived from potential side reactions such as the $[2+2]$ cycloaddition and ene reaction, were detected, which is in sharp contrast to the corresponding intermolecular version.,11 Concerning other organolithium reagents, $s$-BuLi gave lower yield of 7a (entry 2), while PhLi gave comparable results (entry 3). We turned our attention to organomagnesium reagents. The initial attempt with $i$-PrMgCl${ }^{12}$ led to a slow reaction even at room temperature (entry 4). Pleasingly, $\mathrm{Ph}_{3} \mathrm{MgLi}$ improved the yield of $7 \mathrm{a}$ to $69 \%$ yield (entry 5). ${ }^{\mathbf{1 3 , 1 4}}$ Among other solvents tested (entries 6-9), $\mathrm{Et}_{2} \mathrm{O}$ proved to be the solvent of choice, giving $7 \mathbf{a}$ in $87 \%$ yield (entry 6 ).

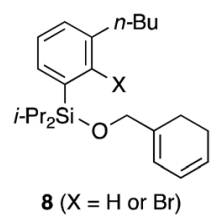




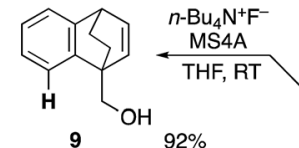<smiles>CC(C)[AsH2]OCc1cccc2c1C1C=CC2CC1</smiles>

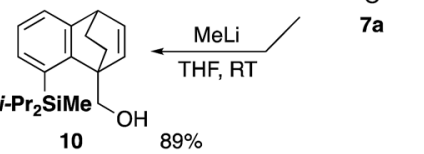

$10 \quad 89 \%$

Scheme 3 Synthetic transformations.

The synthetic utility of cycloadduct 7a was demonstrated by several orthogonal transformations (Scheme 3). The silyl group on 7 a provided an opportunity for further elaboration of the aromatic ring. Indeed, by treating with tetrabutylammonium fluoride in the presence of 4 A molecular sieves, both the silicon-oxygen and silicon-carbon bonds in 7a were cleaved, giving alcohol 9 in 92\% yield. By contrast, methyllithium cleaved only the silicon-oxygen bond to afford alcohol 10 in $89 \%$ yield. Tamao-Fleming oxidation ${ }^{\mathbf{1 5}}$ of $7 \mathbf{a}$ by treatment with $t$-BuOOH and $\mathrm{NaH}$ gave phenol 11 in $79 \%$ yield. In addition, oxidative cleavage of the bridged double bond in $7 \mathbf{a}$ followed by reduction gave diol 12.

Table 2 shows the scope of this tethering strategy. The combination of $\mathbf{4 a}$ with furfuryl alcohol (5b) and pyrrolylmethanol 5c gave precursors $\mathbf{6 b}$ and $\mathbf{6 c}$ in high yields, which underwent the intramolecular $[4+2]$ cycloaddition $\left(\mathrm{Ph}_{3} \mathrm{MgLi}\right.$, $\mathrm{Et}_{2} \mathrm{O}, 0{ }^{\circ} \mathrm{C}, 10 \mathrm{~min}$ ) to give cycloadducts $7 \mathbf{b}$ and $7 \mathbf{c}$ in $90 \%$ and $84 \%$ yield, respectively (entries 1 and 2). Entries 3-5 show variation of the aryl moiety, using the precursors $6 \mathbf{6}-\mathbf{f}$ having a methoxy or a fluoro substituent(s), prepared from chlorosilanes $\mathbf{4 b}-\mathbf{d}$ and alcohol $5 \mathbf{a}$. The reactions of $\mathbf{6 d}$ and $6 \mathbf{e}$, bearing a methoxy and a fluoro group at the meta position to the

Table 2 Substrate scope ${ }^{a}$

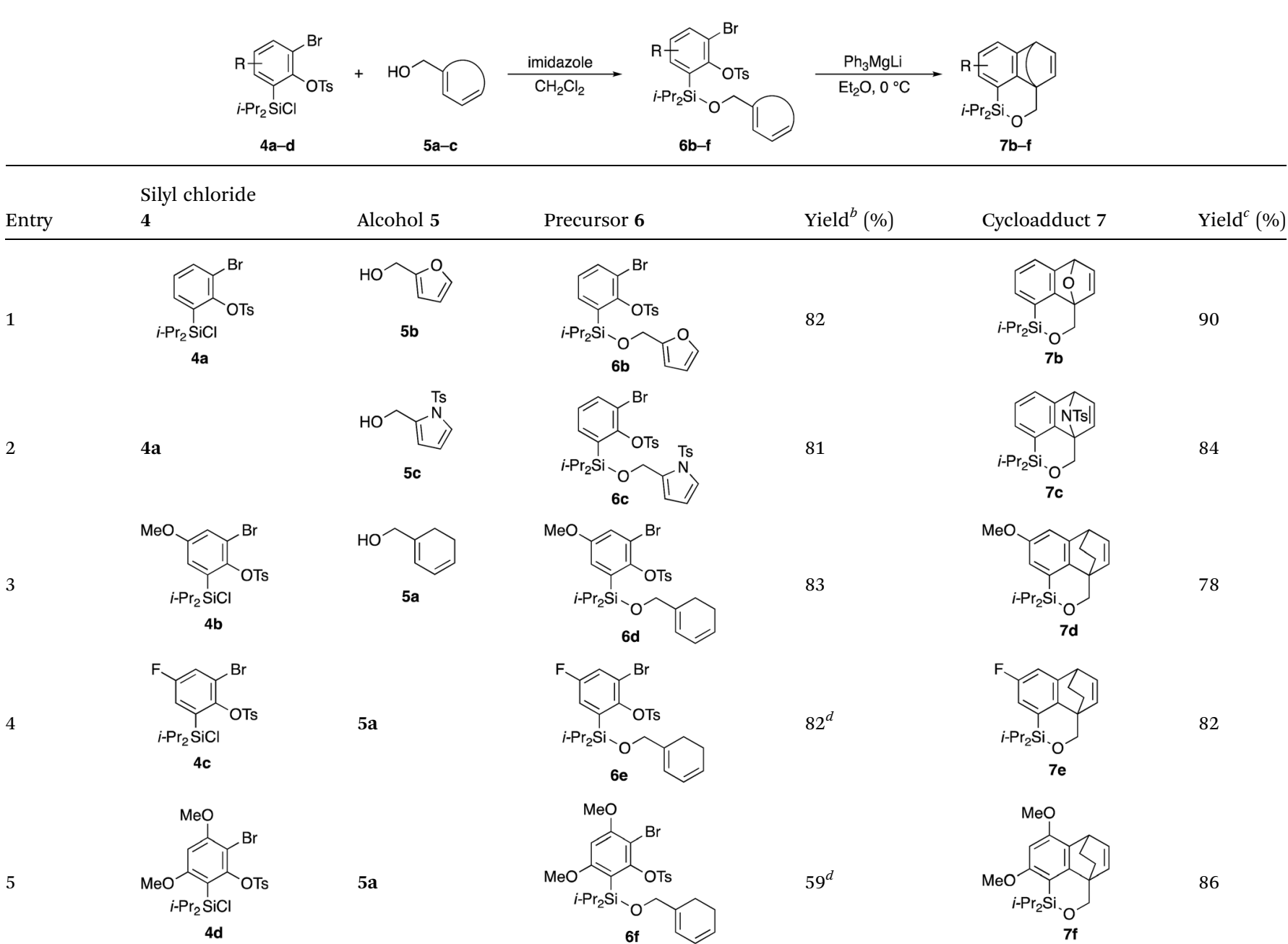

\footnotetext{
${ }^{a}$ Conditions for the preparation of precursors $\mathbf{6 b}-\mathbf{f}$ : see the ESI. Conditions of cycloadditions: precursor 6 (1.0 equiv.) and $\mathrm{Ph}{ }_{3} \mathrm{MgLi}(1.2$ equiv.) in $\mathrm{Et}_{2} \mathrm{O}(0.05 \mathrm{M})$ at $0{ }^{\circ} \mathrm{C}$ for $10 \mathrm{~min} .{ }^{b}$ Isolated yield. ${ }^{c}$ Isolated yield from $6 .{ }^{d}$ Overall yield for two steps from the corresponding arylhydrosilane: chlorination and $O$-silylation.
} 
respective silyl substituents, proceeded smoothly to give cycloadducts $\mathbf{7 d}$ and $7 \mathrm{e}$ both in high yield (entries 3 and 4). The precursor 6f, the ortho, para-dimethoxy derivative, also underwent a clean cycloaddition to give the desired product $7 \mathbf{f}$ in excellent yield (entry 5).

With excellent results obtained with cyclic dienyl arynophiles as discussed above, we further examined the applicability to the substrates with an acyclic diene, often less reactive than the cyclic counterpart, ${ }^{3 c, f, 4 c, f, g, 16}$ which gave interesting results (Scheme 4). When the E,E-diene substrate 13a was treated with $\mathrm{Ph}_{3} \mathrm{MgLi}$ at $0{ }^{\circ} \mathrm{C}\left(\mathrm{Et}_{2} \mathrm{O}, 10 \mathrm{~min}\right)$, a clean $[4+2]$ cycloaddition occurred to give dihydronaphthalene 14a in 77\% yield (Scheme $4 \mathrm{a})$. By contrast, the reaction of the E,Z-congener $\mathbf{1 3 b}$ (THF, 45 ${ }^{\circ} \mathrm{C}, 10 \mathrm{~min}$ ) gave no $[4+2]$ cycloadduct $\mathbf{1 4 b}$, but instead, the $[2+$ 2] cycloadduct 15 , albeit in $49 \%$ yield, which could be rationalized by a cycloaddition followed by $\mathrm{Si}-\mathrm{O}$ bond scission by $\mathrm{Ph}_{2}{\mathrm{Mg}:{ }^{17}}^{17}$ remarkable finding given that, the regioselective $[2+$ 2] cycloaddition of an internal alkene in 1,3-dienes is less common (Scheme $4 \mathrm{~b}$ ). ${ }^{3 c-g}$ The relative trans configuration was verified by ${ }^{1} \mathrm{H}^{-1}{ }^{1} \mathrm{H}$ NOESY experiments.

Furthermore, we addressed the applicability to the synthesis of barrelenes, an attractive class of bicyclic compounds. ${ }^{18}$ The question was whether or not the substrates having an internal arene moiety undergo the $[4+2]$ cycloadditions with dearomatization, and the results are summarized in Table 3. Entries 1 and 2 show the cycloaddition reactions of bromoaryl tosylates 16a and 16b, whose anthracene moieties are tethered at the C9 and the $\mathrm{C} 1$ positions, respectively. Reaction of 16a gave the corresponding triptycene $17 \mathrm{a}$ in $64 \%$ yield (entry 1 ). By contrast, the precursor $16 \mathrm{~b}$ underwent clean cycloaddition at the 1,4position of the anthracene ring to afford naphthobarrelene 17b in $65 \%$ yield (entry 2). Note that here the $\mathrm{C} 1$ position of the anthracene served as the anchor for the tether, and therefore the benzyne reacted with the outer ring (1,4-position), despite the higher reactivity of the central ring (9,10-position).${ }^{19}$ The [ $4+$ 2] cycloaddition of naphthalene as a diene is more challenging than that of anthracene due to higher aromaticity. ${ }^{20}$ Nonetheless the reaction of precursor $\mathbf{1 6 c}$ was realized at an elevated temperature $\left(40{ }^{\circ} \mathrm{C}\right)$, giving dibenzobarrelene $17 \mathrm{c}$ in $51 \%$ yield (entry 3 ).
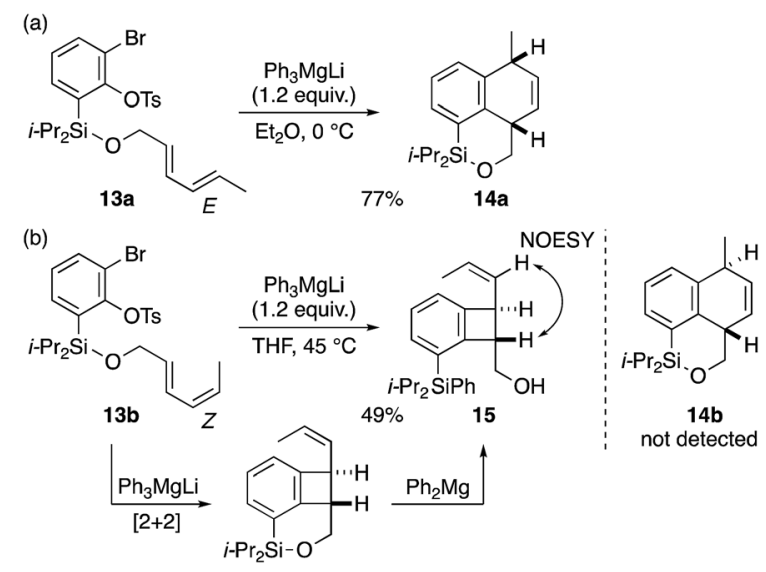

Scheme 4 Reaction with acyclic dienes.

Table 3 Intramolecular cycloaddition with aromatic rings ${ }^{a}$
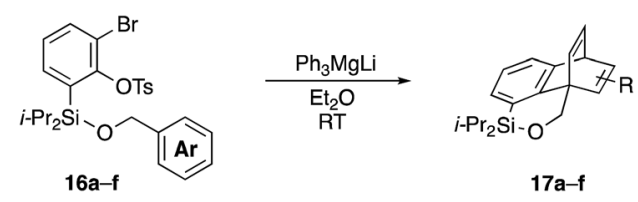

\begin{tabular}{llll}
\hline Entry & 16 & 17 & Yield $^{b}(\%)$ \\
\hline
\end{tabular}

$1^{c}$

2

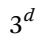

6

5
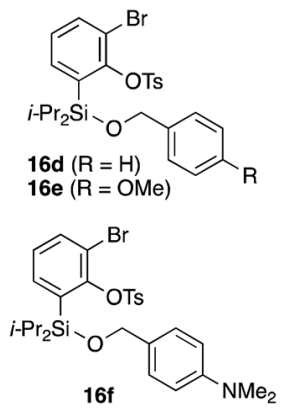

${ }^{a}$ Unless otherwise indicated, reactions were performed with precursor 16 (1.0 equiv.) and $\mathrm{Ph}_{3} \mathrm{MgLi}$ (1.2 equiv.) in $\mathrm{Et}_{2} \mathrm{O}(0.05 \mathrm{M})$ at room temperature for 10 min. ${ }^{b}$ Isolated yield. ${ }^{c}$ In THF at $0{ }^{\circ} \mathrm{C} .{ }^{d}$ At $40{ }^{\circ} \mathrm{C}$.

To explore the limits of this dearomatization, simple benzenes were examined as aromatic diene components (entries 4-6). ${ }^{21}$ The reaction of tosylate $\mathbf{1 6 d}$ with a simple benzene ring resulted in failure, giving no cycloadduct $17 \mathbf{d}$ (entry 4). With a hope of realizing the reaction by increasing the HOMO level of the benzene ring, ${ }^{21 d, 22}$ we examined substrates 16e and 16f, having a methoxy group and a dimethylamino group, respectively. It turned out that $16 \mathrm{e}$ gave no reaction (entry 5), whereas the dimethylamino group worked well for the cycloaddition to give benzobarrelene $\mathbf{1 7 f}$ in $44 \%$ yield (entry 6 ).

\section{Conclusions}

In summary, we have described a silicon-tether strategy for the intramolecular $[4+2]$ cycloaddition of benzynes with dienes. 2Bromo-6-(chlorodiisopropylsilyl)phenyl tosylate, a versatile benzyne platform, plays a key role in the facile assembly of 
various cycloaddition precursors by combining with dienes via a Si-O bond. This strategy would be applicable to various other potential arynophiles, and useful for complex polycyclic natural product syntheses. Further studies along these lines are in progress.

\section{Experimental}

A typical procedure for the internal cycloaddition is described for the reaction of $\mathbf{6 a}$ with $\mathrm{Ph}_{3} \mathrm{MgLi}$ in $\mathrm{Et}_{2} \mathrm{O}$ (entry 6): To a solution of $\mathrm{PhLi}\left(0.67 \mathrm{M}\right.$ in cyclohexane and $\mathrm{Et}_{2} \mathrm{O}, 1.1 \mathrm{~mL}, 0.74$ $\mathrm{mmol})$ in $\mathrm{Et}_{2} \mathrm{O}(1.5 \mathrm{~mL})$ was added $\mathrm{PhMgBr}$ (0.94 M in THF, 0.41 $\mathrm{mL}, 0.39 \mathrm{mmol}$ ) at $0{ }^{\circ} \mathrm{C}$, and the mixture was stirred for $30 \mathrm{~min}$. The resulting solution of $\mathrm{Ph}_{3} \mathrm{MgLi}$ was used in the following experiment. To a solution of bromoaryl tosylate 6 a $(165 \mathrm{mg}$, $0.300 \mathrm{mmol})$ in $\mathrm{Et}_{2} \mathrm{O}(6.0 \mathrm{~mL})$ was added dropwise $\mathrm{Ph}_{3} \mathrm{MgLi}$ (vide supra) via cannula at $0{ }^{\circ} \mathrm{C}$. After stirring for $10 \mathrm{~min}$, the reaction was stopped by adding sat. $\mathrm{NH}_{4} \mathrm{Cl}$ aq., and the mixture was extracted with EtOAc (x3). The combined organic layer was washed with brine, dried $\left(\mathrm{Na}_{2} \mathrm{SO}_{4}\right)$, and concentrated in vacuo. The residue was purified by preparative thin layer chromatography (silica gel, hexane, EtOAc $=98 / 2, \mathrm{x} 2$ ) to afford cycloadduct $7 \mathrm{a}(77.8 \mathrm{mg}, 87 \%)$ as a colorless oil.

\section{Conflicts of interest}

There are no conflicts to declare.

\section{Acknowledgements}

We are grateful to Dr Mark M. Maturi for careful proofreading. This work was supported by the Grant-in-Aid from Japan Society for the Promotion of Science (JSPS) (Grant No. JP16H06351 and JP18K06548).

\section{Notes and references}

\section{R. W. Hoffmann, Dehydrobenzene and Cycloalkynes,} Academic Press, New York, 1967.

2 For the selected recent reviews on aryne, see: $(a)$ H. H. Wenk, M. Winkler and W. Sander, Angew. Chem., Int. Ed., 2003, 42, 502-528; (b) R. Sanz, Org. Prep. Proced. Int., 2008, 40, 215291; (c) T. Kitamura, Aust. J. Chem., 2010, 63, 987-1001; (d) C. Wentrup, Aust. J. Chem., 2010, 63, 979-986; (e) A. Bhunia, S. R. Yetra and A. T. Biju, Chem. Soc. Rev., 2012, 41, 3140-3152; (f) S. Yoshida and T. Hosoya, Chem. Lett., 2015, 44, 1450-1460; (g) J. Shi, Y. Li and Y. Li, Chem. Soc. Rev., 2017, 46, 1707-1719; (h) H. Pellissier and M. Santelli, Tetrahedron, 2003, 59, 701-730; (i) P. M. Tadross and B. M. Stoltz, Chem. Rev., 2012, 112, 3550-3577; (j) C. M. Gampe and E. M. Carreira, Angew. Chem., Int. Ed., 2012, 51, 3766-3778; ( $k$ ) A. V. Dubrovskiy, N. A. Markina and R. C. Larock, Org. Biomol. Chem., 2013, 11, 191-218; (l) A. E. Goetz, T. K. Shah and N. K. Garg, Chem. Commun., 2015, 51, 34-45; (m) J.-A. García-López and M. F. Greaney, Chem. Soc. Rev., 2016, 45, 6766-6798; (n) T. Roy and A. T. Biju, Chem. Commun., 2018, 54, 2580-2594; (o)
H. Takikawa, A. Nishii, T. Sakai and K. Suzuki, Chem. Soc. Rev., 2018, 47, 8030-8056.

3 (a) H. E. Simmons, J. Am. Chem. Soc., 1961, 83, 1657-1664; (b) R. Huisgen and R. Knorr, Tetrahedron Lett., 1963, 4, 10171021; (c) G. Wittig and H. Dürr, Justus Liebigs Ann. Chem., 1964, 672, 55-62; (d) M. Jones Jr and R. H. Levin, J. Am. Chem. Soc., 1969, 91, 6411-6415; (e) P. Crews and J. Beard, J. Org. Chem., 1973, 38, 522-528; (f) P. Crews and J. Beard, J. Org. Chem., 1973, 38, 529-532; $(g)$ E. E. Waali, J. Org. Chem., 1975, 40, 1355-1356; (h) I. F. Eckhard, H. Heaney and B. A. Marples, J. Chem. Soc., 1969, 2098-2104; (i) D. Niu and T. R. Hoye, Nat. Chem., 2014, 6, 34-40.

4 (a) W. M. Best and D. Wege, Tetrahedron Lett., 1981, 22, 48774880; (b) W. H. Darlington and J. Szmuszkovicz, Tetrahedron Lett., 1988, 29, 1883-1886; (c) K. R. Buszek, Tetrahedron Lett., 1995, 36, 9125-9128; (d) K. R. Buszek and D. L. Bixby, Tetrahedron Lett., 1995, 36, 9129-9132; (e) D. E. Kaelin Jr, S. M. Sparks, H. R. Plake and S. F. Martin, J. Am. Chem. Soc., 2003, 125, 12994-12995; $(f)$ M. E. Hayes, H. Shinokubo and R. L. Danheiser, Org. Lett., 2005, 7, 3917-3920; $(g)$ A. B. Smith III and W.-S. Kim, Proc. Natl. Acad. Sci. U. S. A., 2011, 108, 6787-6792; (h) S. Yoshida, K. Shimizu, K. Uchida, Y. Hazama, K. Igawa, K. Tomooka and T. Hosoya, Chem.-Eur. J., 2017, 23, 15332-15335; (i) S. Prévost, A. Dezaire and A. Escargueil, J. Org. Chem., 2018, 83, 4871-4881.

5 (a) H. Nishiyama, T. Kitajima, M. Matsumoto and K. Itoh, J. Org. Chem., 1984, 49, 2298-2300; (b) G. Stork and M. Kahn, J. Am. Chem. Soc., 1985, 107, 500-501; (c) D. Craig and J. C. Reader, Tetrahedron Lett., 1990, 31, 6585-6588; (d) G. Stork, T. Y. Chan and G. A. Breault, J. Am. Chem. Soc., 1992, 114, 7578-7579; for reviews, see: $(e) \mathrm{M}$. Bols and T. Skrydstrup, Chem. Rev., 1995, 95, 1253-1277; (f) L. Fensterbank, M. Malacria and S. M. Sieburth, Synthesis, 1997, 813-854; $(g)$ D. R. Gauthier Jr, K. S. Zandi and K. J. Shea, Tetrahedron, 1998, 54, 2289-2338; (h) M. Parasram and V. Gevorgyan, Acc. Chem. Res., 2017, 50, 2038-2053.

6 (a) C.-L. Chen, S. M. Sparks and S. F. Martin, J. Am. Chem. Soc., 2006, 128, 13696-13697; (b) S. M. Sparks, C.-L. Chen and S. F. Martin, Tetrahedron, 2007, 63, 8619-8635; (c) K. J. Procko, H. Li and S. F. Martin, Org. Lett., 2010, 12, 5632-5635; (d) B. M. O'Keefe, D. M. Mans, D. E. Kaelin Jr and S. F. Martin, J. Am. Chem. Soc., 2010, 132, 1552815530; (e) B. M. O'Keefe, D. M. Mans, D. E. Kaelin Jr and S. F. Martin, Tetrahedron, 2011, 67, 6524-6538.

7 (a) W. Tochtermann, G. Stubenrauch, K. Reiff and U. Schumacher, Chem. Ber., 1974, 107, 3340-3352; (b) T. Matsumoto, T. Hosoya, M. Katsuki and K. Suzuki, Tetrahedron Lett., 1991, 32, 6735-6736.

8 (a) J. L. Speier, J. Am. Chem. Soc., 1952, 74, 1003-1010; (b) G. Simchen and J. Pfletschinger, Angew. Chem., Int. Ed., 1976, 15, 428-429; (c) D. Peña, A. Cobas, D. Pérez and E. Guitián, Synthesis, 2002, 1454-1458.

9 As a leaving group, we revealed that the tosyloxy group gave a better result than the triflyloxy group by an optimization process. For the difference of benzyne generation effected 
by the leaving group of halo-sulfonates, see: T. Hamura, T. Arisawa, T. Matsumoto and K. Suzuki, Angew. Chem., Int. Ed., 2006, 45, 6842-6844.

10 (a) J. A. Tallarico, K. M. Depew, H. E. Pelish, N. J. Westwood, C. W. Lindsley, M. D. Shair, S. L. Schreiber and M. A. Foley, J. Comb. Chem., 2001, 3, 312-318; (b) S. Varaprath and D. H. Stutts, J. Organomet. Chem., 2007, 692, 1892-1897; (c) C. Huang and V. Gevorgyan, J. Am. Chem. Soc., 2009, 131, 10844-10845; (d) S. Lee, H. Lee and K. L. Tan, J. Am. Chem. Soc., 2013, 135, 18778-18781.

11 For comparison of the intra- and intermolecular reactions, the reaction of 2-bromophenyl tosylate with cyclohexadiene was attempted ( $n$-BuLi, THF, $0{ }^{\circ} \mathrm{C}$ ), giving no $[4+2]$ cycloadduct.

12 I. Sapountzis, W. Lin, M. Fischer and P. Knochel, Angew. Chem., Int. Ed., 2004, 43, 4364-4366.

13 (a) K. Kitagawa, A. Inoue, H. Shinokubo and K. Oshima, Angew. Chem., Int. Ed., 2000, 39, 2481-2483; (b) T. Higuchi, K. Ohmori and K. Suzuki, Chem. Lett., 2006, 35, 1006-1007. 14 Other magnesate complex, $n-\mathrm{Bu}_{2}(i-\mathrm{Pr}) \mathrm{MgLi}$, was not effective, and resulted in a low yield of 7 a $(28 \%)$.

15 (a) K. Tamao, N. Ishida, T. Tanaka and M. Kumada, Organometallics, 1983, 2, 1694-1696; (b) K. Tamao, T. Kakui, M. Akita, T. Iwahara, R. Kanatani, J. Yoshida and M. Kumada, Tetrahedron, 1983, 39, 983-990; (c) I. Fleming, R. Henning and H. Plaut, J. Chem. Soc., Chem. Commun., 1984, 29-31.
16 (a) R. R. Schmidt and R. Angerbauer, Angew. Chem., Int. Ed., 1979, 18, 304-305; (b) C. Dockendorff, S. Sahli, M. Olsen, L. Milhau and M. Lautens, J. Am. Chem. Soc., 2005, 127, 15028-15029.

17 A small amount (4\%) of the cis isomer was observed, and other detectable products were the corresponding biphenylene, a homodimer of the in situ generated benzyne, and a phenyl adduct of the benzyne.

18 (a) H. E. Zimmerman and G. L. Grunewald, J. Am. Chem. Soc., 1966, 88, 183-184; (b) E. Ciganek, J. Am. Chem. Soc., 1966, 88, 2882-2883; (c) H. E. Zimmerman, R. S. Givens and R. M. Pagni, J. Am. Chem. Soc., 1968, 90, 6096-6108; for a review, see: (d) H. E. Zimmerman and D. Armesto, Chem. Rev., 1996, 96, 3065-3112.

19 (a) B. H. Klanderman, J. Am. Chem. Soc., 1965, 87, 4649-4651; (b) Y. Tsuchido, T. Ide, Y. Suzaki and K. Osakada, Bull. Chem. Soc.Jpn., 2015, 88, 821-823.

20 (a) R. G. Miller and M. Stiles, J. Am. Chem. Soc., 1963, 85, 1798-1800; (b) P. W. Rabideau, Org. Prep. Proced. Int., 1986, 18, 113-116.

21 (a) D. T. Longone and J. A. Gladysz, Tetrahedron Lett., 1976, 4559-4562; (b) W. J. Houlihan, Y. Uike and V. A. Parrino, J. Org. Chem., 1981, 46, 4515-4517; (c) T. R. Hoye, B. Baire, D. Niu, P. H. Willoughby and B. P. Woods, Nature, 2012, 490, 208-211; (d) V. D. Pogula, T. Wang and T. R. Hoye, Org. Lett., 2015, 17, 856-859.

22 I. Tabushi, H. Yamada, Z. Yoshida and R. Oda, Bull. Chem. Soc. Jpn., 1977, 50, 285-290. 